This item was submitted to Loughborough's Research Repository by the author.

Items in Figshare are protected by copyright, with all rights reserved, unless otherwise indicated.

\title{
Redressing the sleeper effect: evidence for the favorable persuasive impact of discounting information over time in a contemporary advertising context
}

PLEASE CITE THE PUBLISHED VERSION

http://dx.doi.org/10.1080/00913367.2015.1085820

\section{PUBLISHER}

Taylor and Francis / @ American Academy of Advertising

\section{VERSION}

SMUR (Submitted Manuscript Under Review)

\section{PUBLISHER STATEMENT}

This work is made available according to the conditions of the Creative Commons Attribution-NonCommercialNoDerivatives 4.0 International (CC BY-NC-ND 4.0) licence. Full details of this licence are available at: https://creativecommons.org/licenses/by-nc-nd/4.0/

\section{LICENCE}

CC BY-NC-ND 4.0

\section{REPOSITORY RECORD}

Foos, Adrienne, Kathy Keeling, and Debbie I. Keeling. 2019. "Redressing the Sleeper Effect: Evidence for the Favorable Persuasive Impact of Discounting Information over Time in a Contemporary Advertising Context". figshare. https://hdl.handle.net/2134/19633. 


\title{
REDRESSING THE SLEEPER EFFECT: EVIDENCE FOR THE FAVORABLE \\ PERSUASIVE IMPACT OF DISCOUNTING INFORMATION OVER TIME IN A CONTEMPORARY ADVERTISING CONTEXT
}

\section{Adrienne Foos}

Kathleen Keeling

Debbie Isobel Keeling

\begin{abstract}
The shift in the accessibility of positive and negative information about consumer products on the internet calls for a revisiting of persuasion effects. A counterintuitive effect, called the sleeper effect, predicts attitudes toward a persuasive message have the potential to increase in favorableness despite the presence of information discounting the message. An experimental study was conducted to support the existence of the sleeper effect, demonstrate its renewed relevance in the contemporary advertising environment, and provide a foundation for further sleeper effect studies.
\end{abstract}


As early as 1961, the question was being asked: “Does the 'sleeper effect’ apply to advertising?” (Weinberger 1961). The sleeper effect refers to an increase in favorable attitudes over time towards a persuasive message, despite accompanying information refuting the message. Given the importance of persuasion effects to the study of advertising effectiveness, and current interest in the potential for negative information to favorably impact attitudes towards a message (Fransen et al. 2015; Kim et al. 2010); the answer is seemingly 'yes'. Despite early promise of the sleeper effect, replication difficulty and questions of relevance to common advertising conditions (e.g., repetitive television advertisements) led to a wane in sleeper effect research after the 1970s. However, some notable exceptions used the sleeper effect to explain advertising phenomena during this period (Hutchinson and Moore 1984; Mazursky and Schul 1988; Lariscey and Tinkham 1999). More recently, some research considered the persuasive impact of the sleeper effect through entertaining messages and fictional narratives/drama (Appel and Richter 2007; Jensen et al. 2011). Given today’s shifting advertising environment, a replication of the sleeper effect and re-enquiry into the conditions in which it is likely to occur is warranted.

The balance of product-knowledge power between consumer and business has motivated companies to invest heavily in online (especially social media) advertising (Corstjens and Umblijs 2012). Yet, digital media affords consumers enhanced and relatively easy access to and sharing of competitor or non-business approved information (Lovett et al. 2013). Consumers obtain and share much of their product information from multiple media outlets through search 
engines, seeking out both positive and negative information online (Ein-Gar, Shiv, and Tormala 2012; Maehle and Supphellen 2013). For example, consumers are often shown ads online, such as pop-ups, and then later look up the product through a search engine. Amazon.com and TripAdvisor.com clearly show positive and negative customer reviews one after another, blogs detail favorable and unfavorable experiences with products, and people post their opinions about products to their friends on Facebook and Twitter (Chatterjee 2011). Consumers no longer have to expend much effort to find or share information concerning a product. Concern has been raised over the differential impact of the multiple ways in which ads and negative or positive information can be displayed together, beyond advertiser control (Kim et al. 2010; Maehle and Supphellen 2013). Advertisers constantly develop strategies to keep pace with this changing landscape. The shift in both temporal proximity and type of product information available to consumers calls for a review of relevant persuasion effects (Fransen et al. 2015).

This dynamic advertising environment alongside past difficulty in finding the sleeper effect and inconsistent results motivates a re-inquiry into the sleeper effect. The aims of this re-inquiry are to reliably demonstrate the sleeper effect, provide support for its renewed relevance to the contemporary advertising context and elicit conditions favorable to finding the sleeper effect. Addressing these aims contribute to clarifying theoretical disagreement over the logical conditions necessary to produce the sleeper effect and implications for practitioners by bringing understanding to attitude change and persistence over time. The background and hypotheses development expands on the current state of sleeper effect research in advertising, followed by an experimental study and discussion of its implications for the sleeper effect.

\section{BACKGROUND AND HYPOTHESES}




\section{The Sleeper Effect}

In 1949, Hovland and colleagues found opinion change was sometimes greater after a period of time rather than immediately after exposure to a persuasive message, naming this the sleeper effect. The sleeper effect occurs when a persuasive message has a greater delayed impact on attitudes when accompanied by a discounting cue (Lariscey and Tinkham 1999). To explain the sleeper effect, it is hypothesized that a negative cue (e.g., a disclaimer, counterattitudinal message, negative review, low credibility source, or negative product attribute) discounting a persuasive message inhibits the initial positive impact of the message. The discounting cue is separated in memory over time from the message, allowing the message to have a delayed positive impact on attitudes (Kumkale and Albarracín 2004). In an early example, Hovland and Weiss (1951) found participants more positive toward persuasive messages (e.g., advocating selling anti-histamine drugs without a prescription) over time when advocated for by a low credibility source (a mass circulation monthly pictorial magazine), and less positive toward persuasive messages over time when advocated for by a high credibility source (New England Journal of Biology and Medicine). Here, the low credibility source serves as the discounting cue.

Researchers originally predicted that the discounting cue is 'forgotten' at a more rapid rate than message content (Hovland, Lumsdaine, and Sheffield 1949; Pratkanis, Greenwald, Leippe, and Baumgardner 1988). With this forgetting hypothesis, the discounting cue becomes unavailable in memory. If this were the case, experiments would show delayed attitudes in treatment groups converge to a baseline and recall measures would show no memory of the discounting cue. Yet, research showed that the discounting cue was not forgotten (Hovland and Weiss 1951). This result prompted the proposal of the dissociation hypothesis, in which the message and discounting cue may be recalled during immediate post-testing, but are not spontaneously 
associated after a delay (Kumkale and Albarracín 2004; Pratkanis et al. 1988). An increase in the favorableness of attitudes in groups receiving the discounting cue without necessarily forgetting the discounting cue suggests an effect at work beyond forgetting.

Later, researchers proposed the differential decay hypothesis, in which the sleeper effect results when the message and cue have equal initial impact, but the cue decays more rapidly than the message (Pratkanis et al. 1988). The two conditions necessary for the differential decay hypothesis are a) a slower rate of impact decay for the message and discounting cue, and b) weak immediate integration of information from the message and discounting cue (Pratkanis et al. 1988). While the forgetting, dissociation, and differential decay hypotheses are similar in that they refer to retention in memory, they differ in their assumptions of encoding. Delayed opinion change for the dissociation hypothesis assumes a result of retrieval of message information and failure to retrieve dissociated cue information, the decay hypothesis assumes that the impact of the message and cue are poorly integrated at the time of encoding (Pratkanis et al. 1988). All three hypotheses are incomplete in their formulation and do not have supporting empirical evidence. Thus, if the sleeper effect does exist, the underlying mechanism is not understood.

\section{Criticisms of the Sleeper Effect and Sleeper Effect Research.}

A review of sleeper effect literature reveals doubt that the sleeper effect exists, and that evidence of the effect is so difficult to obtain and unreliable that past researchers have favored accepting the null hypothesis. For example, Schulman and Worrall's replications of early sleeper effect studies failed to find an increase in attitudes over time in discounting groups (1970). A series of negative results in experiments by Gillig and Greenwald in 1974 led them to conclude the sleeper effect did not exist. There is also little agreement as to how the discounting should be defined, or 
how different types of discounting cues effect the encoding or processing of the message content (Gruder et al. 1978; Kumkale and Albarracín 2004; Mazursky and Schul 1988). For example, discounting cues have been operationalized as low credibility sources, counter-attitudinal messages, disclaimers, and negative product attributes (e.g., a case of champagne glasses with a dented box (Ein-Gar et al. 2012) and defensive ads (Lariscey and Tinkham 1999).

The robustness of the sleeper effect is questioned with regards to ecological validity, or under what conditions it would occur outside the laboratory (Gruder et al. 1978; Mazursky and Schul 1988). Shadish et al. stated (2002) that "the circumstances under which this effect occurs turn out to be quite limited and unlikely to be of any general interest” (p. 19). As early as 1961, Weinberger questioned the relevance of the sleeper effect for the real-life advertising context as the circumstances in which a persuasive message is immediately followed by a discounting cue was unlikely to occur. That is until the recent rise in use of digital advertising channels. Post 1970s, the sleeper effect was cited as an interesting theory or persuasive effect in advertising (Eisend and Langner 2010; Lariscey and Tinkham 1999) and other mass communication channels (Jensen et al. 2011). The sleeper effect has also been used to describe attitude changes over time (Maehle and Supphellen 2013), rather than the classical sleeper effect of an increase in attitudes when a message is accompanied by a discounting cue. Additional theoretical and empirical work is certainly necessary to fully understand the sleeper effect and its relevance to advertising. Thus, this study develops and employs stimulus materials and instructions more representative of individuals' real experiences, relevant to contemporary everyday advertising.

\section{Replicating the Absolute Sleeper Effect - Hypotheses Development}


In response to contrary findings, Gruder et al. (1978) and Cook, Gruder, Hennigan, and Flay (1979) detail the assumptions of the discounting cue/dissociation hypothesis, distinguish between the absolute and relative sleeper effect and outline the necessary conditions for the sleeper effect:

When: a) a persuasive message has a substantial initial impact on attitudes; b) this change is totally inhibited by a discounting cue; c) the cue and message are dissociated over time; and d) the cue and message are dissociated quickly enough so that the message by itself still has some impact when dissociation occurs (Gruder et al. 1978).

\section{PLACE FIGURE 1 ABOUT HERE}

These logical conditions offer more stringent guidelines for sleeper effect claims (Jensen et al. 2011). Figure 1 illustrates three possible effects. The absolute sleeper effect, in which attitude change increases over time in groups exposed to a discounting cue versus a no message control group. The relative sleeper effect, in which attitude change increases over time in the discounting cue group versus the message only group (Cook et al. 1979; Pratkanis et al. 1988). If there is no increase in persuasion compared to the no message group, then maybe attitudes are decaying to baseline attitudes rather than an actual change in attitudes. The non-persisting boomerang effect is when there is an initial attitude change opposite to that promoted, and then increased persuasion over time towards the baseline (Kumkale and Albarracín 2004; Pratkanis et al. 1988). Thus, for the absolute sleeper effect, the message + discounting group must show lower initial attitudes than the message only group, and an increase in positive attitudes over time compared to the no message group. For the absolute sleeper effect, we hypothesize:

Hypothesis 1: There will be an absolute increase in positive attitudes over time for those presented with a message and discounting cue compared to no message baseline attitudes. 


\section{Ordering.}

An important issue is the order of presentation of the message and discounting cue. Advertising research suggests that the discounting cue is most effective when presented after the original message (Lariscey and Tinkham 1999). Previous research suggests the primacy/recency of countervailing messages affects information processing and persuasion over time (Haugtvedt and Wegener 1994; Pratkanis et al. 1988). The belief adjustment model generally shows the recency effect when individuals are asked to make an immediate judgment based on the content of sequential messages (Hogarth and Einhorn 1992). If individuals tend to base initial attitudes on the recency of information, the discounting cue following the message is more likely to inhibit the positive impact of the message, a basic condition for the absolute sleeper effect, thus:

Hypothesis 2: The order of presentation of the discounting cue will affect the absolute sleeper effect, such that the effect occurs when the discounting cue follows the message but not when the discounting cue is presented before the message.

\section{EXPERIMENTAL METHODOLOGY}

\section{Stimuli.}

The structure of the advertisement and discounting cue derive from those described in Mazursky and Schul's (1988) sleeper effect article. The choice of product for the experiment was determined both through pre-testing and current market conditions. To identify a realistic and familiar packaged food product, an online sample of 58 American adults listed three different packaged foods, without regard to their feelings about the products. They also listed attributes to describe the foods to provide material relevant to what consumers expect to see regarding the products to help craft the message. The most frequently listed items were T.V. dinners (14 \%), 
meat products (such as meatballs, beef jerky, etc.) (11\%), and frozen pizza (9\%). Attributes of packaged foods frequently mentioned were: flavor (20\%), texture (16\%), convenience (16 \%), healthy (12\%), and variety (4\%). A search of the most frequently listed products revealed ready meals and meat products as prohibitively broad categories for the scope of this experiment. The frozen pizza search revealed advertisements in the marketplace associated with the launch of a gluten-free pizza base in the UK that also contained discounting cues. The launch had not yet begun in the US, although gluten-free alternatives to popular foods are growing. Based on insights from the pretest and a search of real gluten-free pizza ads, an advertisement was crafted consisting of a photograph of a pizza and a verbal message advocating the purchase of the pizza by listing its advantages on three key attributes. The stimulus is presented below.

\section{PLACE STIMULUS ABOUT HERE}

Previous sleeper effect research in the consumer field uses disclaimers from consumer protection agencies to discount advertisements (Mazursky and Schul 1988). This experiment discounts the advertisement using a disclaimer from a fictional consumer protection group as follows: "The health claims of Ciao's gluten-free pizza are unsubstantiated, and have never been tested by nutritionists. In fact, adopting a gluten-free lifestyle can result in nutrition deficiencies and even weight gain. Furthermore, customers have complained about the lack of flavor of Ciao's pizza.”

A robust test of the absolute sleeper effect needs a discounting cue entirely negating the message. A second pretest $(\mathrm{n}=75)$; between groups study, with a no message, message only, and message + discounting group, with attitudes as a dependent measure) showed the desired outcome of an attitude baseline in the no message group, $(\mathrm{M}=4.83$; $\mathrm{SE}=.37)$, low attitudes in the message + discounting group $(\mathrm{M}=4.93 ; \mathrm{SE}=.40)$ and a significant attitude increase for the message only 
group compared to the other two groups $(\mathrm{M}=7.19 ; \mathrm{SE}=.36)(\mathrm{F}(2,72)=12.327, \mathrm{p}<.001)$. This establishes the potential for the main experiment to find an absolute sleeper effect.

Participants.

Respondents were recruited through a research firm to requested sample demographics: 1) roughly even gender split; 2) 18 and over in age; 3) a range of ages included. 171 participants completed the first session and 98 completed the second session of the experiment (attrition rate of $43 \%)$. Data screening resulted in the removal of 18 outliers, leaving a total sample of 80.

There are more males (58\%) than females (42\%) in the sample, which, though perhaps a little higher than expected, is not wholly inconsistent with the continuing disparity between male and female internet use in developed countries (http://www.internetworldstats.com/usage.htm). Nonetheless, the sample age group profile differs from that of US internet users (http://www.census.gov/history/pdf/2013computeruse.pdf/), with rather more in the 46-64 age group (53\% vs. 35\%) and less in the 18-35 age group (17\% vs 30\%). Therefore, we examined the data for potential biases finding no systematic differences by age or gender in willingness to eat frozen pizza, frequency of eating frozen pizza or familiarity with the term gluten free.

\section{Design, Procedure and Measures.}

A mixed design [(no message group; message only group; message + pre-discounting cue group; message + post-discounting cue group) $\mathrm{x}$ (time)] experiment was conducted. The study was presented to participants as a “consumer response survey” (Mazursky and Schul 1988) to direct marketing via the internet (Ein-Gar et al. 2012). After reading the participant information sheet, agreeing to take part in the research and be re-contacted, participants in treatment groups first 
read an advertisement advocating a new, fictitious gluten-free pizza. Participants in discounting cue groups received a message from a fictitious consumer protection group either before or after the ad. Participants then filled out the dependent measures and indicated their attitudes toward the pizza and beliefs regarding gluten-free pizza. At time two, about 11 days later (average 10.94 days), participants were invited to what was presented as a follow-up survey. They completed the same attitude and belief measures (but without the stimuli).

Independent measures. The ordering of the advertisement and discounting cue was manipulated in the experiment to aid in defining the sleeper effect boundaries in the context of this research.

Starting with the premise that the conditions for exposure to proximal messages happens more frequently (e.g., with access to online reviews or banner ads), we still need to incorporate a delay to assess the sleeper effect. The time delay refers to the length of time between the immediate post-test measurements and the (repeated) delayed post-test measurements. Kumkale and Albarracin (2004) conclude that the mean interval between immediate post-test and the delayed post-test for sleeper effect studies is eighteen days (2004). The length of time delay must balance being long enough for dissociation to occur but short enough for information to still be accessible in memory and other related factors. Given that contemporary advertising conditions have changed (e.g., with shorter and more frequent ads), the time delay for the sleeper effect to take place is also likely to be impacted, that is, a relatively shorter period than in previous decades. The trend is evident in sleeper effect studies over time. Studies in the 1950s-1960s use periods of 4-6 weeks (e.g., Hovland and Weiss 1951) whereas those in the 1980s use periods of 1-10 days (Pratkanis et al. 1988, Mazursky and Schul 1988). Thus, we study the effect over 10-12 days. 
Dependent measures. Attitudes toward the pizza for both post-tests used on a six-item, 7-point semantic differential scale (bad/good, unpleasant/pleasant, negative/positive, unfavorable/ favorable, undesirable/desirable, dislike/like) $(\alpha=.91)$.

Other measures. Beliefs regarding gluten-free pizza were measured along two dimensions ("To what extent does a gluten-free lifestyle contribute to health?” and “To what extent does eliminating gluten impact taste?”) (9-point scales from very unhealthy to very healthy; and taste reverse coded, from very good tasting to very bad tasting) (Wood, Kallgren, and Preisler 1985). Critically, access to attitude-relevant beliefs impacts the ability of persuasive messages to influence attitude judgments (Wood et al. 1985). Mazursky and Schul (1988) advocate entering beliefs as covariates in the ANOVA. We therefore controlled for beliefs in this experiment to minimize potential biases against the product choice. An analysis revealed no significant effect of the measured demographic questions on the dependent variable.

\section{Results}

Hypothesis 1 predicts an increase in the favorability of attitudes in a discounting group compared to no increase in the no message group. To test this hypothesis, both a statistical test of the effects of time and group on attitudes for all groups, and a comparison of means over time in the discounting and no message groups are needed. A repeated measures ANCOVA analyzed the within and between groups factors on attitudes. Initial beliefs in the health $(\mathrm{M}=4.84)$ and taste ( $M=6.05$ ) of a gluten-free lifestyle are controlled by adding as a covariate. The main effect of Time is significant $(\mathrm{p}<.05)$, and there is a significant interaction between time and group ( $\mathrm{F}(1$, $74)=3.802, \mathrm{p}<.05)$. This means both the passage of time and the interaction between time and group affect attitudes. Figure 2 shows an increase in attitude means for the message + post- 
discounting group (initial $\mathrm{M}=5.32$, delayed $\mathrm{M}=5.87$; SE: .34 ) compared to the no message group (initial $\mathrm{M}=5.35$, delayed $\mathrm{M}=5.45$; $\mathrm{SE}=.31$ ). A paired t-test confirmed the significant increase in attitude favorability over time in the message + post-discounting group (t (16) -1.894, $\mathrm{p}<.05$ one-sided) compared to no significant change in attitudes over time in the no message group, substantiating the observation of the absolute sleeper effect.

\section{PLACE FIGURE 2 ABOUT HERE}

Supporting Hypothesis 2, attitudes in the message + pre-discounting group (initial $\mathrm{M}=5.70$, delayed $\mathrm{M}=5.17$; SE: .30) do not increase compared to the no message group, contrasting the finding of the absolute sleeper effect for the message + post-discounting group. This evidences that the absolute sleeper effect occurred when the discounting cue followed the message but not when that cue came before the message. Message only group attitudes significantly decay (initial $\mathrm{M}=6.34$, delayed $\mathrm{M}=5.51$; SE: .30; $(\mathrm{t}(20)=3.661, \mathrm{p}<.01))$ over time.

\section{DISCUSSION}

The study successfully re-examines and supports the classic absolute sleeper effect formulation: initial lower attitudes in the message + post-discounting group increase over time in comparison to the no message group where attitudes stay constant over time. It replicates earlier sleeper effect findings within a contemporary advertising context and with more stringent logical requirements (e.g., a strong discounting cue) (Cook et al. 1979). The findings counter assertions from previous research and address criticisms of the effect by showing that an absolute sleeper effect can be found, that the effect occurs in a relevant context, and that it is more likely to occur when the discounting cue follows the message. 
Finding an absolute sleeper effect supports the discounting cue/dissociation hypothesis.

Discounting occurred, because any initial positive attitude change caused by the message was inhibited by the discounting information. This aligns with a meta-analysis confirming the logical requirement of a strong discounting cue to find the sleeper effect (Cook et al. 1979; Kumkale and Albarracín 2004), and counters more recent research using only weak negative information to enhance the persuasiveness of positive information (Ein-Gar et al. 2012). Moreover, we can argue that dissociation occurred, because the increase in attitudes over time in the message + post-discounting group compared to the no message baseline implies that the discounting cue is less accessible than the message topic in the delayed post-test (Kumkale and Albarracín 2004).

The study results also suggest that the criticism of limited circumstances and interest (Shadish et al. 2002) is no longer relevant. Past sleeper effect experiments do not reflect current real life situations (Gruder et al. 1978; Pratkanis et al. 1988). In the Mazursky and Schul (1988) and Gruder et al. (1978) experiments, from which the present study borrowed methodological components, the sleeper effect was only found in highly elaborative conditions, in which participants viewed multiple images, read lengthy messages (often repeatedly), and were induced to elaboratively process the material. For example, the Mazursky and Schul (1988) experiments used 1-5 color pictures and describe 5-8 attributes appropriate for the advertising context at the time (magazines). The current consumer environment includes short, often conflicting information presented in temporal proximity online. Thus, our experiment, whilst replicating sleeper effect criteria from past experiments, was specifically designed to mimic the contemporary advertising context, using short messages, less elaborative conditions, one picture and 3 attributes. This suggests that the sleeper effect is relevant, of interest to researchers and marketers, and that the circumstances in which the sleeper effect occurs have come to fruition. 
Further, we are not only replicating the absolute sleeper effect but also to some extent testing the boundary conditions for the effect by demonstrating it within shorter/less elaborative conditions.

The study also shows that the absolute sleeper effect is more likely to occur when the discounting cue follows the message rather than when the cue is presented before the message. One explanation is that the discounting cue preceding the message signals to the recipient that upcoming information is unreliable, and is therefore unnecessary to process (Priester, Wegener, Petty, and Fabrigar 1999). This also shows a boundary of dissociation: it does not occur when the discounting cue precedes the message. Nonetheless, there are many possibilities for future research on the effects of multiple messages with varied valence on consumer attitudes.

There are several potential explanations for the increased positive attitudes in the postdiscounting cue group. A potential explanation of the increase in positive attitudes is increased associations and elaboration due to the presence of negative information. Future research could investigate mediating factors of the sleeper effect. A limitation of the sleeper effect is that we tested two time periods. Though there is a significant increase in positive attitudes in the postdiscounting cue group away from the baseline no message group, there may be an inverted ' $U$ ' relationship, where the upward trend would return back to the baseline attitude. The short, single time delay between times 1 and 2 was chosen due to the nature of the product category. It is plausible that a positive-attitude-based purchase could occur within or near the time frame. We chose not to add post-tests due to potential validity issues. The no message group serves as a measure of baseline attitudes towards the category. Attitudes in the message only group move toward the baseline, suggesting the positive attitudes as a result of viewing the advertisement were short-lived. Yet, attitudes in the post-discounting cue group begin at the baseline and then become more positive; suggesting the discounting cue has a more persistent impact on attitudes. 
Finally, future research might investigate the influence of consumer motivation and processing factors on the sleeper effect and whether the effect holds in other areas of (online) advertising, such as the travel industry, where emotional appeals and customer reviews are widespread. 


\section{REFERENCES}

Appel, Markus, and Tobias Richter (2007), "Persuasive Effects of Fictional Narratives Increase Over Time," Media Psychology, 10 (1), 113-134.

Chatterjee, Patrali (2011), "Drivers of New Product Recommending and Referral Behavior on Social Network Sites," International Journal of Advertising, 30 (1), 77-101.

Cook, Thomas D., Charles L. Gruder, Karen M. Hennigan, and Brian R. Flay (1979), "History of the Sleeper Effect: Some Logical Pitfalls in Accepting the Null Hypothesis," Psychological Bulletin, 86 (4), 662-679.

Corstjens, Marcel, and Andris Umblijs (2012), "The Power of Evil," Journal of Advertising Research. 433-449

Ein-Gar, Danit, Baba Shiv, and Zakary L. Tormala (2012), "When Blemishing Leads to Blossoming: The Positive Effect of Negative Information," Journal of Consumer Research, 38 (5), 846-859.

Eisend, Martin, and Tobias Langner (2010), "Immediate and Delayed Advertising Effects of Celebrity Endorsers' Attractiveness and Expertise," International Journal of Advertising, 29 (4), 527.

Fransen, Marieke L., Peeter W. J. Verlegh, Amna Kirmani, and Edith G. Smit (2015), "A Typology of Consumer Strategies for Resisting Advertising, and a Review of Mechanisms for Countering Them," International Journal of Advertising, 34 (1), 6-16.

Gillig, Paulette M., and Anthony G. Greenwald (1974), "Is it Time to Lay the Sleeper Effect to Rest?" Journal of Personality and Social Psychology, 29 (1), 132-139.

Gruder, Charles L., Thomas D. Cook, Karen M. Hennigan, Brian R. Flay, and Jerome Halamaj (1978), "Empirical Tests of the Absolute Sleeper Effect Predicted from the Discounting Cue Hypothesis," Journal of Personality and Social Psychology, 36 (10), 1061-1074.

Haugtvedt, Curtis P., and Duane T. Wegener (1994), "Message Order Effects in Persuasion: An Attitude Strength Perspective," Journal of Consumer Research, 21 (1), 205-218.

Hogarth, Robin M., and Hillel J. Einhorn (1992), "Order Effects in Belief Updating: The BeliefAdjustment Model," Cognitive Psychology, 24, 1-55.

Hovland, Carl I., Arthur A. Lumsdaine, and Fred D. Sheffield (1949), Experiments in Mass Communication, New York: Wiley.

Hovland, Carl I., and Walter Weiss (1951), "The Influence of Source Credibility on Communication Effectiveness," Public Opinion Quarterly, 15(4), 635. 
Hutchinson, J. Wesley., and Danny L. Moore (1984), "Issues Surrounding the Examination of Delay Effects in Advertising, Advances in Consumer Research, 11, 650-655.

Jensen, Jakob D., Jennifer K. Bernat, Kari M. Wilson, and Julie Goonewardene (2011), "The Delay Hypothesis: The Manifestation of Media Effects Over Time," Human Communication Research, 37 (4), 509-528.

Kim, Jooyoung, Hye Jin Yoon, and Sun Young Lee (2010), "Integrating Advertising and Publicity," Journal of Advertising, 39 (1), 97-114.

Kumkale, G. Tarcan, amd Dolores Albarracín (2004), "The Sleeper Effect in Persuasion: A Meta-analytic Review," Psychological Bulletin, 130 (1), 143-72.

Lariscey, Ruth Ann Weaver, and Spencer F. Tinkham (1999), "The Sleeper Effect and Negative Political Advertising," Journal of Advertising, 28 (4), 13-30.

Lovett, Mitchell J. , Renana Peres, and Ron Shachar (2013), "On Brands and Word of Mouth," Journal of Marketing Research, 50 (4), 427-444.

Maehle, Natalia, and Magne Supphellen (2013), "Advertising Strategies for Brand Image Repair: The Effectiveness of Advertising Alliances," Journal of Marketing Communications, 1-13.

Mazursky, David, and Yaacov Schul (1988), "The Effects of Advertisement Encoding on the Failure to Discount Information: Implications for the Sleeper Effect," Journal of Consumer Research, 15 (1), 24-36.

Pratkanis, Anthony R., Anthony G. Greenwald, Michael R. Leippe, Michael H. Baumgardner (1988), "In Search of Reliable Persuasion Effects: III. The Sleeper Effect is Dead. Long Live the Sleeper Effect," Journal of Personality and Social Psychology, 54 (2), 203-18.

Priester, Joseph, Duane Wegener, Richard Petty and Leandre Fabrigar (1999), "Examining the Psychological Process Underlying the Sleeper Effect: The Elaboration Likelihood Model Explanation," Media Psychology, 1, 27-48.

Schulman, Gary I., and Chrysoula Worrall (1970), "Salience Patterns, Source Credibility, and the Sleeper Effect," Public Opinion Quarterly, 34 (3), 371-382.

Shadish, William R., Thomas D. Cook, and Donald T. Campbell (2002), Experimental and Quasi-experimental Designs for Generalized Causal Inference, Boston: Houghton Mifflin Company.

Weinberger, Martin (1961), "Does the "Sleeper Effect" Apply to Advertising? Journal of Marketing, 25 (6), 65-67.

Wood, Wendy, Carl A. Kallgren, and Rebecca Mueller Preisler (1985), "Access to AttitudeRelevant Information in Memory as a Determinant of Persuasion: The Role of Message Attributes," Journal of Experimental Social Psychology, 21 (1), 73-85. 


\section{FIGURE 1}

Absolute, Relative and Non-Persisting Boomerang Effects

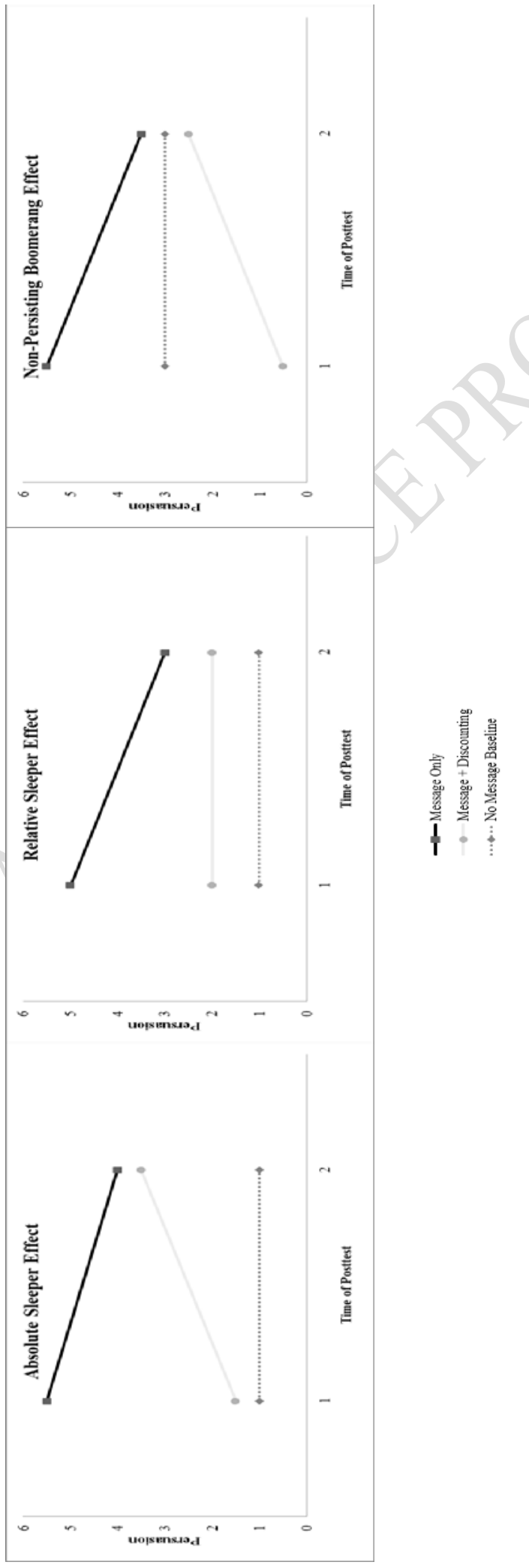


FIGURE 2

Experiment ANCOVA

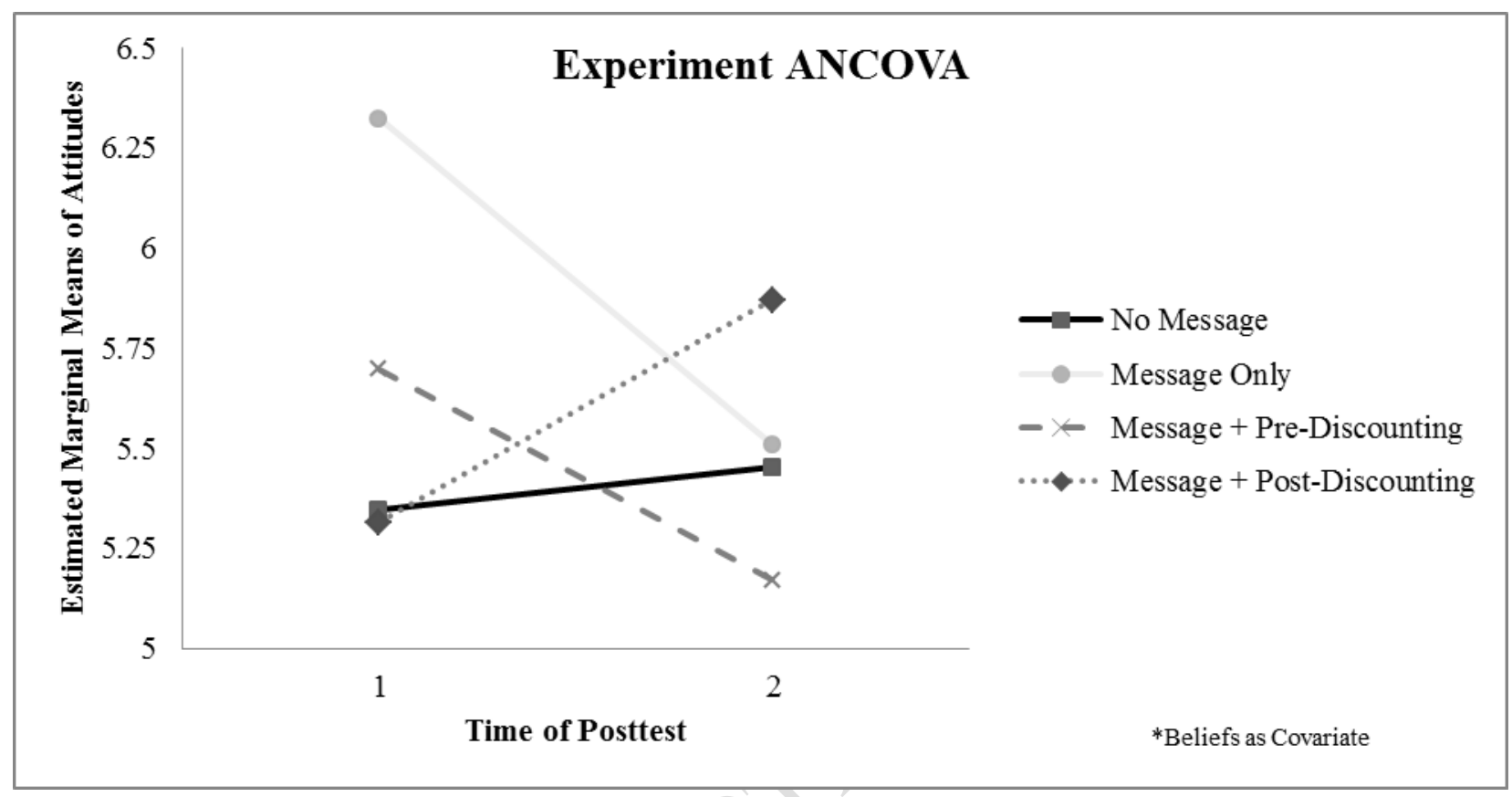




\section{APPENDIX}

\section{Advertisement Stimuli}

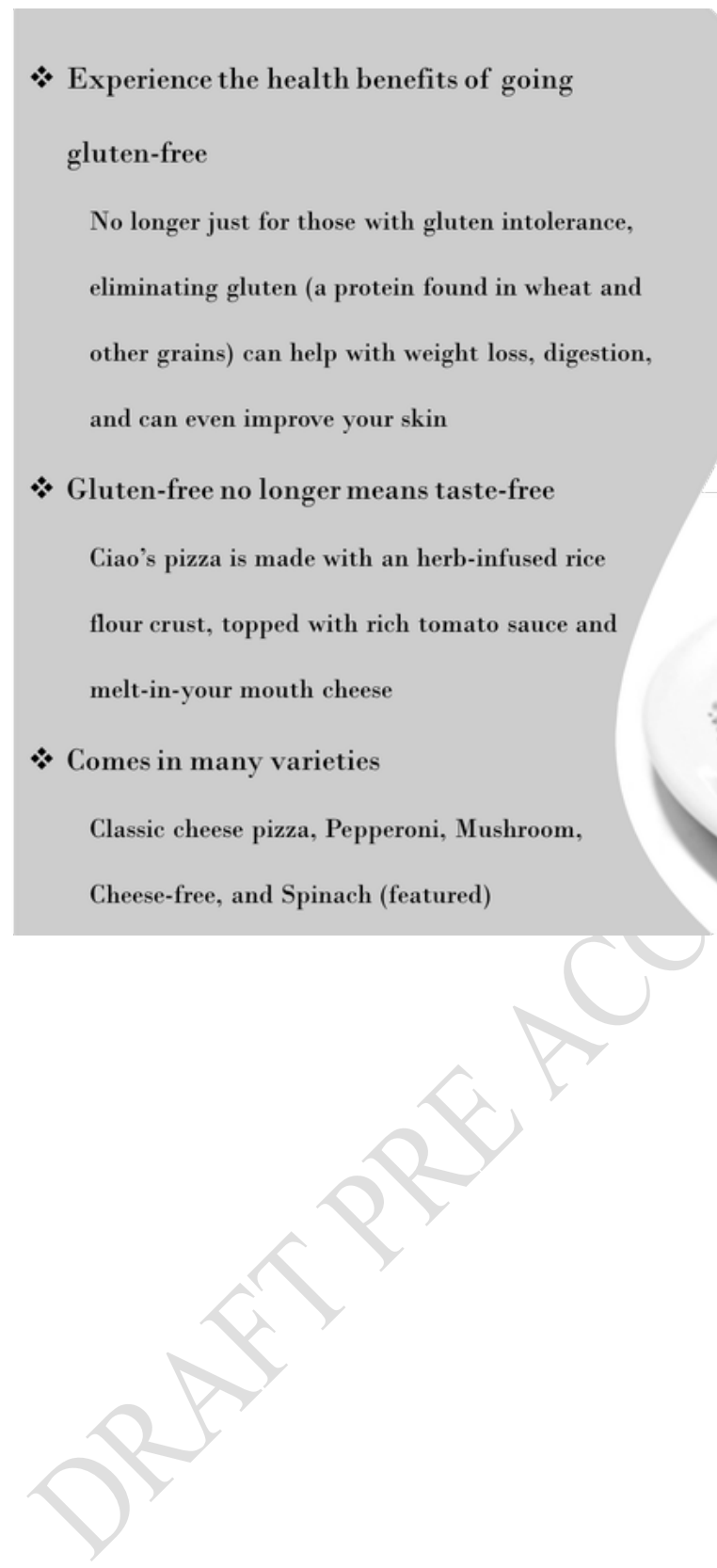

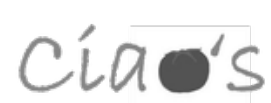

Gluten-Free Pizza

$A$ healthy taste of Italy

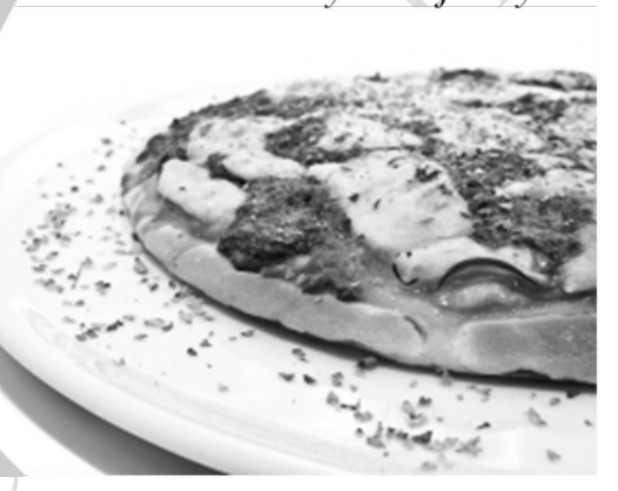

